\section{Francisco \\ Jarauta}

\title{
WALTER BENJAMIN: MITO Y ESCRITURA
}

El pensamiento de Walter Benjamin está marcado por la extraterritorialidad. Su mirada es medúsica, inquietante, saturniana, capaz de congelar las cosas para después abrir en ellas una especie de interioridad imprevista. Su gesto es el del pensar que se atreve, se arriesga a detener la dialéctica para posibilitar el aparecer de un orden en el que se inscriben las mediaciones ocultas, los azares, esa interminable secuencia de otros que, para Benjamin, constituyen la verdadera historia de las formas.

Es como si los objetos -sea el fetiche del interior burgués o los esplendores de la galería grandvilliana, el enigmático espejo barroco o el último gesto surrealista- fueran arrancados de su flujo natural e introducidos en un imaginario Bildraum absoluto, en el que penetra aquella "iluminación profana”, que en ningún caso equivale a un nuevo espacio inventado, sino al tiempo del devenir histórico, entendido ahora como el verdadero territorio del crítico. Situar el objeto cerca y lejos de 
la tradición que lo ha ordenado en el jardín del progreso, en la naturalidad de su aparecer o en el museo de los bienes culturales, para abandonarlo después al devenir material en el que se configura, como arrastrado por aquella máquina cuya lógica no es otra que la regida por la necesidad de dar forma a la experiencia, sea cual sea su destino, tal es la intención de su mirada.

No se trata de reanimar el mundo para restituirlo a la comprensión o experiencia de un nuevo sujeto, sino de rescatar otra historia, en cuyo relato -la historia de las formas- se expresa ahora en su tensa y laberíntica representación. La recherche proustiana, que tanto atrae y subyuga a Benjamin, es justamente un análisis inmenso, despiadado, del poder mágico de los indicios, tras los que se nos da la experiencia de un no-regreso, del irreparable fluir del tiempo y de la inasible vida de la memoria.

Surgen así verdaderos mapas imaginarios, sobre los que se aplica aquella mirada microscópica, acompañada siempre de un infatigable dominio, propio de un refinado literator, como le gustaba decir de sí mismo con desenfadada coquetería. Acaso no son mapas imaginarios las lucidísimas páginas sobre el Trauerspiel, los laberintos indescifrables de su Passagen-Werk o sus glosas sobre Kafka. Y acaso no es su vida una especie de extravío, que va de su infancia berlinesa al París de sus últimos años, extravío que, según confiesa, coincide con la realización de sus sueños, cuyas primeras huellas fueron los laberintos marcados en los papeles secantes de sus libros de ejercicios.

La fascinación de persona y oeuvre, como dirá Adorno, no ha dejado más salida que la atracción magnética o la defensa estremecida. Bajo la mirada de sus palabras se transforma todo, mostrándose en su tensión abismal. Todo lo que escribió suena como si el pensamiento recogiera las 
promesas de los cuentos y los libros infantiles, que tanto gustaba coleccionar. Puede entenderse como el rastreo obstinado de las huellas del verdadero extravío, como es el naufragio de la proustiana promesse de bonheur, inscrito en todo aquello que en la cultura ha perdido la fuerza de la vida. Benjamin penetró la máscara de las apariencias de lo concreto, para descubrir tras ellas el rostro del concepto extraviado, en el instante mismo de su emergencia o derrumbe. Pensador del dazwischen, de los espacios intermedios, hace suyo el conflicto de los extremos, en el que se explicita, como en ningún otro lugar o momento, la tensión entre mito y experiencia, que sin duda constituye el eje principal de su escritura.

Sabedor de cómo las energías nihilistas de la época moderna hacen de todo ruinas y fragmentos, no duda en afirmar que "la cantidad de significado está en proporción exacta a la presencia de la muerte y al poder de la descomposición". Frente a este destino -“so es kommt, es kommt, es ist die Katastrophe!"- surge el gesto de su escritura, sin otra intención moral que la de organizar el pesimismo. Política y metafísica, teología y materialismo, mito y modernidad, erudición y especulación extravagante, se ven convocadas a la hora de intentar la reconstrucción y genealogía de lo moderno. Y esto no en servicio de fáciles y complacientes restauraciones -el "érase una vez" que domina el burdel del historicismo debe entrar en tensión con el presente-, sino como disposición crítica para abordar el "estado de excepción” que domina la época.

Este nuevo saber crítico se instala en un mundo de heterogeneidades infinitas que, en su conjunto, Benjamin intenta transformar, si bien promesa y dialéctica deben quedar suspendidas. Nos es dado tan sólo ese tiempo-intermedio kafkiano, el "mientras tanto" benjaminiano como lugar y tiempo de la emergencia de la historia y del destino. Benjamin 
sabe bien que el precio de la esperanza es la vida y que sólo así cada época sueña la siguiente. Debe ser por esto que el pensamiento de Benjamin suscita tanto terror cuanta felicidad promete.

\section{II}

La relación entre proceso de formalización, lenguaje y vanguardia artística domina la investigación de Walter Benjamin. A su luz adquieren nuevas dimensiones aspectos tan diferentes como la matriz lógica del barroco, el drama del lenguaje en Kafka o el destino expresionista de la ciencia positiva del lenguaje artístico. Frente a una tradición dominada por el uso de categorías analíticas, la dispositio benjaminiana introduce una serie de conceptos que, en su conjunto, definen de una forma rigurosamente nueva la tarea y el programa de la crítica.

La tensión que atraviesa las formas del arte hay que buscarla en la relación entre la experiencia artística y las estrategias de la representación, que regulan el proceso general de la cultura. Es esta economía la que, en última instancia, explica las variaciones de la forma y su representación. Esta hipótesis de trabajo, absolutamente ajena a cualquier fácil sociologismo, introduce a Benjamin en un aleatorio complejísimo, en cuya exploración se verá obligado a explicitar piezas fundamentales de su método como son su concepción del lenguaje, de la experiencia y del tiempo.

El origen del drama barroco alemán es la oportunidad que tiene Benjamin para hacer una primera, y casi definitiva, aclaración de principios. Una lectura de la "Premisa epistemológica", que acompaña al texto, en efecto, nos sitúa ante la lógica de un procedimiento crítico, cuya eficacia Benjamin intenta mostrar. Aquí, el interés no es tanto analizar la positividad de la forma del arte Trauerspiel (drama barroco), sino el de 
establecer la lógica del proceso que modifica el sistema de los signos, es decir, la forma de la representación correspondiente a la experiencia barroca. La estrategia alegórica que domina la forma del Trauerspiel introduce a Benjamin en la perspectiva de un proceso más amplio, que atraviesa el conjunto de las formas de la cultura. La supuesta unidad de una experiencia, interpretada convencionalmente desde el tribunal de la razón cartesiana, se fragmenta ahora y se nos muestra bajo formas varias, que Benjamin define como dramáticas en el sentido barroco del término. La estrategia alegórica no es entendida entonces sólo como una modificación del orden del lenguaje artístico, sino como una modificación más profunda del orden mismo de la experiencia. La cultura de la identidad, regida por la transparencia derivada de la adecuación del lenguaje y el mundo -que Foucault ha analizado detenidamente-, se cubre ahora de una opacidad creciente. Frente a la transparencia del mundo renacentista, la dificultad del habitar barroco, de un mundo cada vez más laberíntico y dramático.

El análisis benjaminiano intenta ser el gesto crítico que haga surgir los ritmos de los tiempos: esos rostros inscritos, huellas y rastros que quedan grabados en el lenguaje, como si éste fuera una lámina sensibilísima, que precisa de la intervención crítica para hacerlos visibles. De alguna manera, Benjamin es fiel a la tradición hebrea para la que el método histórico sigue siendo un método filológico, en cuya base está el libro de la vida. Y "leer lo que no ha sido jamás escrito", dirá Hofmannsthal de Benjamin, su verdadero intento. No por otras razones, la historia es entendida no sólo como una ciencia, sino, y sobre todo, como una forma de la memoria: la forma anfibia del tiempo.

Por otra parte, el tratamiento de la alegoría barroca le presta a Benjamin la ocasión de polemizar con toda una filosofía del arte dominada por la 
tradición romántica del primado del símbolo como "aparición de la idea", como unidad de objeto sensible y suprasensible, como lenguaje del infinito. A la tesis romántica Benjamin opone una dialéctica en reposo y el reconocimiento de la ambigüedad de lo no resuelto, es decir, de aquella experiencia que debe ser pensada en su tensión dramática.

En efecto, la alegoría no es una modalidad de designación, no es una técnica para producir un determinado sistema discursivo, sino la escritura misma: una escritura fragmentaria, hecha de citaciones, incapaz de constituirse en el nombre de las cosas, sino apenas gesto, voz, en los que aparece temblorosamente la historia. El único nombrar que se nos da es la forma del ensayo en la que resuena la historia del mundo en su acontecer provisional, hipotético, aleatorio. Lo alegórico representa la historia del mundo "abandonado de Dios". Es la écriture du désastre blanchotiana, bien próxima a la cultura hebrea mitteleuropea de las primeras décadas del siglo, para la que la historia se ve marcada por el signo de una inseguridad radical, pensada como catástrofe y ruina.

El espacio de lo alegórico, entendido como escritura e infinita alusividad es también el espacio de los juegos lingüísticos, de las técnicas. Explicar, mostrar la infinidad de variaciones, relaciones, etc., no es otra cosa que desarrollar las potencialidades del lenguaje, entendido como expresión de la vida. El espacio “abandonado de Dios”, el espacio alegórico, se llena de estos juegos y variaciones produciendo una nueva transparencia de las formas. Al poder del Nombre se contrapone el Kunstwollen barroco: esa voluntad de forma y representación artística que -alegóricamentese constituyen en un sistema de representación del mundo.

Del drama barroco al surrealismo, pasando por el spleen baudeleriano o la memoria involuntaria de Proust, traza Benjamin el eje de otra historia, recorrida por una penetrante línea de sombra, en la que la tensión del 
tiempo de la experiencia moderna se explicita en la fluctuación de las formas del arte, registros fieles de una experiencia, en cuyo imaginario, dice Benjamin, sólo quedan las huellas de Dios paseando por el Paraíso.

Es una mirada perdida, nadie sabe si de esteta fetichista o soñador, la que recorre esta línea de sombra que, desde una geografía imaginaria, atraviesa la experiencia moderna. Ante la mirada benjaminiana, la región de la prometida transparencia se ve ahora ensombrecida por el gesto de quien, al internarnos en una suerte de laberinto, nos hace sentir un continuado temblor, una dificultad propia de lo moderno para darse un nombre. Y aventurándose a recorrer esta dificultad elige como propias aquellas figuras que hacen más explícita su intensidad, como son: esa pieza para tristes, que es el Trauerspiel, la metrópoli baudeleriana o esa última instantánea de la inteligencia europea que es el surrealismo.

Es la aventura de quien piensa que un doble deseo domina la historia de la humanidad: hacer transparente el mundo y próxima la proustiana promesse de bonheur, esa forma de la felicidad que da motivos a la esperanza y a la acción, al tiempo que dignifica el mundo. Junto a esta seguridad, otra certeza: ni la transparencia del mundo es algo que acompaña a la experiencia de la razón humana, ni la promesa de felicidad deja de ser ese horizonte perdido en el que renace el mito. Experiencia y mito se constituyen así en el eje articulador de la nueva perspectiva crítica que anima y orienta el proyecto benjaminiano.

Pensar el mito que habitamos, describir sus estrategias narrativas, la lógica de sus formas de representación, es el objeto de la crítica. Contra toda tentación de positivización de los lenguajes artísticos, las formas del arte aparecen ahora en su más radical tensión: inscritas en aquella experiencia previa que las anima y que debe entenderse como la experiencia de un límite, iluminado ahora desde la verdad del mito. 
Desde El origen del drama barroco alemán hasta los ensayos sobre Proust, Kafka o el París de Baudelaire, se desarrolla un detenidísimo, paciente, microscópico análisis de aquellas formas de la cultura, tras las que aletea una especie de historia natural del hombre moderno, cuya dimensión queda cifrada sea en la categoría barroca, sea en la mágica fantasmagoría del intérieur burgués. No se trata de reconstruir una historia, atentos e interesados por poseer su verdad, sino que lo que la crítica busca es mostrar aquellos procedimientos que rigen la construcción de las formas de la experiencia moderna, la historia de su acontecer, entendido, dice Benjamin, en su verse expuesto al tiempo en tanto momento de resolver la tensión de la experiencia en la dimensión de la forma que se constituye como su destino, destino una y otra vez suspendido.

La lejanía del Paraíso, la imposibilidad del nombre esencial, del poder nombrar/conocer el mundo en su sentido más fuerte, es decir, en el del nombrar esencial de Dios, centra esa línea de fuga por la que discurre toda la concepción benjaminiana del lenguaje y sobre la que define su concepto de crítica. Esta se presenta como travesía, Umweg, recorrido oblicuo, atento a las huellas, rastros, Spure, a los que se refiere en las Tesis sobre la filosofía de la historia. A la fluctuación del sistema de la experiencia le acompaña la tensión y la variación de la forma de la cultura y del arte. A la pérdida de transparencia del mundo le acompaña el emerger de aquellos procedimientos alegóricos que deciden la aparición del nuevo espacio dramático que es el Trauerspiel. La felicidad que se le niega al hombre barroco se corresponde con la tristeza, melancolía, del alma barroca, perdida en la selva de los nombres, incierta a la hora de decidir un camino, un método para la travesía del mundo. 
Sin embargo, la verdad se resiste a ser proyectada en el reino del conocimiento. Benjamin insiste una y otra vez en esta frontera del lenguaje. Este es sólo cifra del mundo, figura. Tras él, sigue abierto el fluir de la vida, el orden de las cosas, el silencio o el grito del alma. Su rostro se hace escritura en la mediación del discurso. Y su sentido remitirá siempre a aquella conciencia del límite, representada en la experiencia de la muerte. No es posible reconstruir el Nombre, y el tentativo de Proust, por hacer revivir la autenticidad de la experiencia en el horizonte de un tiempo originario, naufraga. Sólo desde la renuncia al Paraíso cobra fuerza esa nueva figura o nombre de la experiencia -la "pobreza", dirá Benjamin- que permite a Proust romper el cerco mágico de los nombres, el tiempo lineal y homogéneo que aquellos representan. A este discurrir del tiempo, al fluctuar de la nueva experiencia, le acompaña la errancia del nombrar, del narrar, desde la provisionalidad rigurosa del tiempo que Benjamin reconoce en las figuras del discurso de Kafka.

"Las alegorías son en el ámbito del pensamiento lo que las ruinas son en el ámbito de las cosas", comenta Benjamin. A la mirada que recorre el laberinto alegórico se muestran las huellas-rastro de una experiencia por la que ha pasado la vida, razón por la que despiertan en nosotros aquella piedad por la que amamos el tiempo pasado. Pero ningún lugar ni tiempo pasado son ya habitables. Y la mera confirmación de lo infinitamente igual es ya sabotaje de la idea misma de felicidad. Queda el tiempo de esa nueva pobreza, cuyo rostro ilumina otra vez, desde el juego de los nombres, el experimento de una finitud que no renuncia a la promesa de felicidad. Aunque, dirá Benjamin, los sueños no deben realizarse. 